\title{
The Roles of Aesthetic Experience in Elementary School Science
}

\author{
Britt Jakobson • Per-Olof Wickman
}

Published online: 23 March 2007

(C) Springer Science + Business Media B.V. 2007

\begin{abstract}
The role of aesthetic experiences for learning was examined in elementary school science. Numerous authors have argued for a science education also involving aesthetic experiences, but few have examined what this means empirically. Recordings of children's talk with each other and with the teacher during hands-on activities in nine different science units were made. How the children and teachers used aesthetic judgements and how these judgements were part of aesthetic experiences of the science assignments were analysed. For the analysis a pragmatist perspective was used, especially drawing on Dewey and the later Wittgenstein. The results showed how aesthetic judgements occurred in moments of anticipation and moments when the science activities were brought to fulfilment. In this way children used aesthetic judgements normatively about what belonged in science class and what to include and exclude. In this way aesthetic judgements were an important part of learning how to proceed in science class. In using aesthetic judgements the children also talked about their own place in science class and whether they belonged there or not. In this way aesthetic experience is tightly related to learning science as participation. Learning science also meant learning a special kind of aesthetics, that is, learning how to distinguish the science context from other contexts. The fact that children liked or disliked something outside school did not necessarily mean that it was experienced aesthetically in the same way in school, but needed to be re-learnt. What these results mean for science education is discussed at length. The connection between aesthetics and learning to observe is also briefly discussed.
\end{abstract}

Keywords Aesthetic experience $\cdot$ Elementary school $\cdot$ Dewey $\cdot$ Science learning

B. Jakobson $(\bowtie) \cdot$ P.-O. Wickman

Department of Curriculum Studies and Communication, Stockholm Institute of Education, Box 34103, 10026 Stockholm, Sweden

e-mail: britt.jakobson@lhs.se 


\section{Introduction}

In this article we examine how aesthetic experiences, that is, what we find beautiful/ugly and what we find pleasure/displeasure in, are involved when children learn science. In doing this we examine aesthetic aspects of science education in its own right during discourse in elementary school classes during hands on, guided inquiry science tasks. Hence, in this paper we are not examining how aesthetic practices like poetry or art may enrich science education.

It may seem of marginal interest to study the connection between aesthetic experiences and science. Gardner (1971) maintained that art chiefly is the execution of private moods, whereas science mainly concerns the prior conceptualisation of factors relevant to the solution of a problem with a single solution. Posner and co-workers (e.g., Posner et al. 1982; Strike and Posner 1992) acknowledge the role of motivation and values for conceptual change, but still insist on a theory of learning that is fundamentally a theory about the kinds of evidence that function in a rational appraisal of various ideas (Strike and Posner 1992). Likewise Novak (2002, p. 549) maintained that "meaningful learning involves substantive, non-arbitrary incorporation of concepts and propositions into cognitive structure." Thus, according to these views, a study of aesthetic experiences in science education could only deal with how private motivation and emotions can be encouraged so as to produce a student that is willing to learn science. These positions risk excluding aesthetic experiences from the learning process on purely rational and nonempirical grounds (cf. West and Pines 1983). It also detaches meaning-making and learning from action, its social setting and life as a whole.

However, to an increasing extent aesthetic experiences are taken into consideration not only in science education, but also in reports about the scientific endeavour itself. Such positions often draw on the significance scientists make of aesthetic experiences in their autobiographies (e.g., Root-Bernstein 1989; Tauber 1996; Wickman 2006). In line with this numerous authors have argued for a science education also involving aesthetic experiences (Alsop and Watts 2003; Girod and Wong 2002; Lemke 2001; McClure and Zitlow 1991; Szybek 1999; Wong et al. 2001). Girod and Wong (2002, p. 200), using a Deweyan perspective, argued that "science can be taught in ways that borrow from aesthetic and artistic pedagogy to tap the power of aesthetic experience" and so lay the foundation for another and more aesthetic kind of understanding. Lemke (2001) argued that we cannot ignore aesthetics and emotion if the aim is to humanize science education and to make it open for all. Considering these arguments it is of interest to examine empirically the role that aesthetic experiences actually have for meaning-making and learning science beyond merely that of motivation.

Some of the few empirical studies made on aesthetic meaning-making in science education point towards the continuity of aesthetic experience with learning science in this wider sense. Szybek (1999) studied secondary school teenagers dissecting squids. Here aesthetics was involved in making a "nice arrangement" of the squid to overcome feelings of disgust. This arrangement shared qualities with that of the kitchen and of eating animals. Hence, the aesthetic experience needed to be transformed into a nice one. This involved some creativity and learning on part of the students, where prior aesthetic experiences in the kitchen were used in the school lab, helping these children to go on with their activity in science class.

Another example comes from Bloom (1992). In interviews with children about earthworms he demonstrated that emotions, values and aesthetic experiences (EVAs) were 
inter-related and associated with conceptual aspects of learning. One of the examples Bloom (1992, p. 410) gave was:

In other instances the child's own reaction to earthworms involved strong EVA responses. Emily's initial reaction was that they were "ugly, tiny, I don't like the color." As you may recall, she then compared the color to that of a finger with its circulation cut off and to that of a dead body. The outcome was one of inferring that blood was helping to create the color. EVA responses make strong connection with the child. If the color had not evoked such a response, Emily may not have made the connection with blood.

This example makes it clear that a negative aesthetic experience can have positive learning outcomes, and is not merely functioning as a motivational state that halts learning. Aesthetic experiences are evidently involved when students make selections about what is noticed and what is ignored, a central aspect of learning. Cognitive and aesthetic aspects evidently can be entwined when learning is not just seen as a finite, mental outcome, but part of an, often contingent, learning process that needs to be seen as part of a whole activity.

Such a constitutive role for aesthetic experiences in learning gains further support in an empirical study of university students during practical work in science (Wickman 2006). It was shown how learning science means learning a new kind of aesthetics, closely tied to learning how to proceed in science class and learning the subject content. Situations where such learning occurred were regularly aesthetic experiences, where students used aesthetic judgements in communicating the direction and preferences of their undertakings.

The specific role of aesthetic experiences for personal transformation and learning about one's own place in relation to an activity finds support in socio-culturally oriented studies. Bourdieu (1984) studied the taste of people with different upbringing and education. His results suggest that education, through the learning of aesthetic distinctions (i.e., taste) entails the formation of social identity. Hence, learning a certain taste and to experience aesthetically is not just a personal matter, but an important part of being educated within a certain area. Similar effects on identity are found in science education. Cobern and Aikenhead (1998) reported about students who did not experience that science was about nature, because nature as opposed to science was beautiful and something that you could be joyously a part of. This suggests a connection between learning conceptually about the relationship between nature and science on the one hand and aesthetic experience on the other hand. It also points towards a relationship between learning science and learning who you are in relation to science.

So, what we find significant in the now mentioned studies is that these researchers did try to empirically examine the continuity of aesthetic experiences with meaning-making and the learning process more generally as part of the practices of science class. Seen in this way, we argue that aesthetic experience should be an important ingredient when teachers follow children's learning, conceptually as well as emotionally. The purpose here is to build on these earlier studies and further examine the little studied role of aesthetic experiences in learning science in action in class. We will specifically focus on normative aspects, that is, learning what is relevant and not relevant in science class and what are the right and wrong ways to proceed. At the same time this perspective looks at learning as a corollary of participation, as those things that might be promoting a child in proceeding with an activity, also might be promoting participation or vice versa. Besides, to give a more complete picture 
of the roles of aesthetic judgements in science class, we also briefly demonstrate how children and teachers use aesthetic judgements in describing qualities of what is observed.

\section{Theoretical Framework}

In this study we analyse the role of aesthetic experiences of a science class by using a practical epistemology analysis (Wickman 2004; Wickman and Östman 2002a). This methodology builds on the works of Dewey, the later Wittgenstein and socio-cultural stances. Learning is seen as part of a meaning-making process where the units of analysis are actions as situated in communication and in whole activities (Wertsch 1995). Pragmatically we also see talk and communication as action, because when we say something, we do something that has a purpose and consequences as part of an activity. Moreover, we share Lave's (1996) notion about learning as a constantly ongoing unproblematic process, when people are interacting with the world. The problem is instead concerned with what direction learning is taking in relation to a chosen purpose (Rogoff 1990). Accordingly learning occurs all the time, but often along unanticipated paths in undesired directions.

A research agenda like this shares many ideas with the work of Dewey, where experiences are continually transformed in interaction with what occurs, because no two situations are exactly identical. Due to this transformation, we are continually learning something new, which is Dewey's (1938/1997) principle of continuity. Dewey (1934/1980) conceived of an experience in a holistic way entailing transaction with the situation as a whole, as enacted and undergone as part of an activity with a purpose. Hence, every experience and learning is not merely cognitive, but always, also includes values, emotions and doing. In this way aesthetic experience is an inevitable part of an experience that make sense. To decide the direction of our activities, we also need to decide about how we feel about them. In doing them, such aesthetic judgements about our actions also have a normative aspect (i.e., how one should act), including what are the right things to do and what are the relevant entities to notice and discern to go on with the act. Dewey (1934/ 1980 , p. 55) suggested that positive aesthetic experiences regularly were associated with moments of anticipation and moves towards consummation and fulfilment of activities. Accordingly, it is of crucial importance to study aesthetic experiences, because they deal with students' anticipations of how to proceed and also about what counts as fulfilment of purposes and aims, which are normative for action and for what students can learn.

But how can aesthetic experiences be studied? Fortunately, people do not always keep their aesthetic experiences to themselves, but they are regularly communicated and shared as aesthetic judgements. We here define aesthetic judgements as concerning the beautiful/ ugly and pleasure/displeasure in line with Wittgenstein (1966). It is in this connection to language that Wittgenstein functions as an addition to Dewey's principle of continuity. According to Wittgenstein the meaning of a word or an utterance is its use in a language game, which is the activities into which language is woven (Wittgenstein 1967, p. 5). This also goes for aesthetic judgements (Wittgenstein 1966, p. 2). So if we want to know about the meaning of aesthetic experiences we need to look at how aesthetic judgements actually are used. To sum up, the theoretical framework presented here suggests that by studying how aesthetic judgements take part in furthering classroom activities, it is possible to study the various ways in which aesthetic experiences may influence children's learning of science. 


\section{Analytic Approach}

The practical epistemology analysis is developed for analysing the process of meaningmaking and learning (Wickman 2004; Wickman and Östman 2002a). Similar commitments are shared with many other methods to analyse classroom discourse (e.g., Mortimer and Scott 2003; Roth and Lucas 1997; Säljö and Bergqvist 1997). However, based on a theoretical mechanism for the learning process as discourse change, a practical epistemology analysis has developed a certain heuristic to analyse the learning process. Particularly it involves what entities in experience learners use and what this means for deciding how to proceed with the activity. In line with Lave's (1996) and Rogoff's (1990) conception of learning, practical epistemology analysis thus is specifically designed to analyse the direction learning takes as a result of the situated interactions occurring in the classroom. Practical epistemology analysis has been used earlier to track the learning process (Jakobson and Wickman 2007; Lidar et al. 2006; Wickman 2004, 2006; Wickman and Östman 2002a,b).

The terminology of a practical epistemology analysis is based on four operational concepts, namely stand fast, relations, gaps and encounters (Wickman and Östman 2002a). What stands fast in a language game is what is immediately intelligible to the interlocutors. What is immediately intelligible is operationally evident when the interlocutors do not ask each other about what is meant by the words used. Words, whose use stands fast and whose meaning is clearly understood in this way can be seen being used by the interlocutors when construing new relations to them. The relation construed is the meaning that the interlocutors make. For example the children in this study can be seen to say (turns 55-57):

Emma: I think this is the head.

Julia: Yeah, that's the head.

Emma: Yes, look!

In this example the words "this" and "head" can be seen to stand fast to the children. They are used without further questioning about what they mean. To the children in this situation, these words work well to construe a relation about where the head is situated on the earthworm, that is, in learning where the head is on the earthworm. That it makes such sense to both children is evident from the response of Julia, who replies with the same relation, although with a slightly different wording. That they agree on this relation is evident from the consequences that it has through the communicative responses of the children. If the words had not stood fast here, Julia would have been seen to ask questions to Emma about the meaning of the words she used, like "What do you mean by 'this'?" or "Could you show me better where?" If no words stand fast in the end, no new relations can be construed and the activity comes to a halt. The conversation and the activity then have to deal with other things and take new directions. What stands fast can also be a problem if the two persons actually mean different things, but nevertheless go on with the activity. It should be observed that the relation that the children here construed and hence learnt does not necessarily have to be correct from a scientific perspective. A practical epistemology analysis is an analysis of the actual first person epistemologies of the students. However, the meanings that are actually made can be made available for reflection about how alternative meanings could have been made if we consider from a third person perspective, for example, that of the science education researcher or of the teacher, that other meanings were more desirable.

To construe a relation, people first need to see that they need one to proceed with an activity. They can then be seen to notice a gap. For example, in the earlier conversation 
between Emma and Julia they can be seen to have noticed the gap about what the head looks like on real earthworms. When a relation is construed, the gap is said to be filled. Most gaps are filled in the immediate way given above: the children simply construe a relation. Gaps may also be framed explicitly as questions (e.g., "Can you see the head on the earthworm?"). Gaps are not always filled and when this happens, gaps are said to linger. The direction of the learning process can be seen as dependent on a rhythm of noticing certain gaps and filling them with certain relations. Making children see certain gaps is a prerequisite for helping children find and learn the relations of the curriculum. However, it is also necessary that they fill them with relations that take their learning in a direction that leads in desired directions, furthering children's experiences according to the purposes of the activity.

When people notice gaps and fill them with relations, certain encounters can be seen to occur. An encounter is what can be observed to meet in a particular situation, like objects, events and the prior experiences of students and teachers. In the conversation above there is an encounter between the prior experiences of Julia and Emma (in terms of the familiar words they choose to use), but also an encounter between Julia and Emma and the real earthworm.

\section{The Study Settings}

We present results from sound recordings made in five different Swedish schools. These schools represent a wide variety of settings including a big city school, three different medium sized town schools and one in a rural area. One of the medium sized town school areas were dominated by first generation immigrants from the Middle East and north eastern Africa. Hence, the classes represent a wide range of social backgrounds. Seven different classrooms were visited by BJ during one semester. Four classrooms were visited once, two were visited twice and one classroom was visited three times, resulting in about $25 \mathrm{~h}$ of recordings. Children of all classes except two were 6-8 years old (Swedish grade 1 and 2). The exceptions were one class of age 9 (grade 3 ) and one class of 10 year old children (grade 4).

During the visits the children were involved in hands-on inquiry units in biology, chemistry, physics, and earth science working in pairs or small groups during lessons from 40 to 50 min long. This means that in each class audio-recordings were made of 2-5 group conversations during each visit. The units were Changes (the transformation of matter), Solids and Liquids, Electric Circuits, Mixing and Separating, Buds, Shadows and Soil. All of the discussions in pairs or small groups were audio-recorded with a microphone at their desk, most of which were transcribed. Sometimes though it was very hard to hear what the children said as they were talking in a low voice. In addition the voices of the children sometimes were very similar, and occasionally they might have been confused in the transcripts. To facilitate correct interpretation of audio transcripts BJ was present in the classrooms during recordings, observing children's actions at large and taking notes of what occurred to facilitate interpretation of some recordings. Transcriptions given in the text have been translated from Swedish to English trying to preserve the original flavour and connotations of words used. All occasions on which the children used aesthetic judgements were analysed in light of the theoretical considerations mentioned earlier.

Although aesthetic judgements can be communicated in many different modes, not only by using words with aesthetic meanings, but also for example through body gestures or facial expressions, for simplicity we have restricted ourselves to aesthetic word use and the 
Table 1 The frequency of the children's use of aesthetic judgements when doing science in the different classes studied

\begin{tabular}{lcccc}
\hline Unit & $\begin{array}{l}\text { Number of } \\
\text { groups in class }\end{array}$ & $\begin{array}{c}\text { Duration of the } \\
\text { lesson (min) }\end{array}$ & $\begin{array}{l}\text { Number of aesthetic } \\
\text { judgements }\end{array}$ & $\begin{array}{c}\text { Mean time (min) between } \\
\text { aesthetic judgements }\end{array}$ \\
\hline $\begin{array}{l}\text { Shadows } \\
\begin{array}{l}\text { Solids and } \\
\text { liquids }\end{array}\end{array}$ & 3 & 40 & 6 & 20.0 \\
$\begin{array}{l}\text { Mixing and } \\
\text { separating }\end{array}$ & 3 & 40 & 92 & 2.2 \\
$\begin{array}{l}\text { Buds } \\
\text { Changes }\end{array}$ & 2 & 40 & 71 & 1.7 \\
$\begin{array}{l}\text { Soil: } \\
\text { earthworms }\end{array}$ & 5 & 40 & 15 & 5.3 \\
$\begin{array}{c}\text { Soil: soil } \\
\text { types }\end{array}$ & 4 & 50 & 78 & 3.2 \\
$\begin{array}{c}\text { Soil: soil } \\
\text { types }\end{array}$ & 4 & 40 & 89 & 1.8 \\
$\begin{array}{c}\text { Electric } \\
\text { circuits }\end{array}$ & 4 & 40 & 143 & 1.1 \\
\hline
\end{tabular}

relations that are established by using them. The meaning of the aesthetic judgements used is clear both from the intonation and from the context.

When presenting the results of this study we are commenting on intonations concerning the interjections used, putting clarifications in parenthesis. Otherwise we, in the perspective of a practical epistemology analysis, describe what children and teachers are meaning when using aesthetic judgements, for example, "neat" or "disgusting" from their situational use and their consequences, without asking what they "really" mean by the words used. Accordingly we are analysing the aesthetic judgements uttered to see how they are related to the scientific content at hand, to the proceedings in class and to children's possibility of participating.

\section{Results}

Just to demonstrate that aesthetic judgements were not exceptional events, we here first present data showing that children frequently used aesthetic judgements when talking about what occurred as part of their science assignments. Typically a student group used aesthetic judgements every 1-5 min (Table 1). An exceptionally low frequency was found in the unit Shadows. In this article though, we are not examining the reasons for the sometimes, low frequency of aesthetic judgements uttered by teachers or children. However, it can be noted that the low frequency of aesthetic judgements from children in the Shadows unit was correlated with the fact that the teacher during this lesson gave a dissociated and uninvolved impression. The same teacher also taught the same class the Solids and Liquids unit, and here the teacher was much more engaged, which resulted in more frequent use of aesthetic judgements. This should be enough to suggest that the low frequency is not due to the culture of the class, but rather a function of the specific settings. Teacher frequencies are problematic to quantify because we did not specifically record teacher talk apart from when 
directed to the recorded student groups. Nevertheless, in some classes teachers used aesthetic judgements as often as every 2 min, when talking to children.

Under the captions that follow we present examples of the different kinds of roles aesthetic experiences had in these classes. We start by discussing their role in learning norms of science class, first in moments of anticipation and consummation and then as parts of negative aesthetic experiences. The following sections in turn deal with the use of aesthetic judgements by the teachers, their role for children's participation, and for children's understanding of purpose, and finally when children describe what they observe. Aesthetic expressions are emphasised in italics in the excerpts.

\section{Anticipation and Consummation}

In using aesthetic judgements the children talked about what they personally liked or disliked. Although an important role of aesthetic judgements, this observation is trivial and part of the definition of the concept of aesthetic judgements we have given. What we are interested in here is to look beyond this definition and see how these aesthetic judgements are a part of the activity and of children's lives and what this means for what they learn in science. To start looking into what this mean, we can look at an example from the unit Changes, where the children should mix vinegar and water, respectively, with baking soda to see what happened. The overall aim in the unit was that the children should be acquainted with what a mixture is and that substances react differently when mixed with different liquids. A general excitement with talk and laughter arose. Sara, Martin and Julia summed up what happened, both by noting the factual relations and by using aesthetic judgements:

1. Sara: Bubbles are coming.

2. Martin: Look! It's bubble water. It's carbonic acid. ${ }^{1}$

3. Sara: Wow! [excited] Jeez, that's wild!

4. Martin: That's carbonic acid. Can we touch it?

5. Julia: Wait! Wow! [excited]

If we look at these judgements simply as expressions of what the children like and as subjective, inner emotions, it is obvious that Sara is saying that she likes that bubbles are coming and that Julia apparently also likes something in this situation, although it is not clear what exactly. This seems to suggest that at least Sara and Julia here are motivated, although it is less clear what Martin likes about the situation. However, seeing this situation from a Deweyan standpoint means that these aesthetic experiences are part of the activity as a whole. Wittgenstein says a similar thing in suggesting that we should take a closer look not on what the words represent in terms of specific objects or inner feelings, but how they gain their meaning from their use in the activity as a whole. We should therefore not only judge each statement by the children as isolated propositions of facts, but as parts of the

\footnotetext{
1"Carbonic acid" [kolsyra] is a literal translation of the words children used to describe this phenomenon. We have chosen this literal translation because the everyday expression that is used in Swedish to say that a beverage is "carbonated" is to say that it is "with carbonic acid." So it is natural for Swedish children to name bubbles that appear in water as "carbonic acid," although the term has no meaning as to the chemical composition of the bubbles.
} 
communicative situation as a whole, where the children are talking about what is happening, taking their activity according to purpose further.

Seen in this way the children here can be seen to use positive aesthetics to evaluate what is happening in relation to the direction their learning is taking. The children have mixed vinegar and baking soda and something is happening, which according to the purpose they also are able to see. They can even describe what is happening by making relations to bubbles and to carbonic acid, which are words that stand fast from prior experiences. Obviously the children in this moment are making prior experiences continuous with the current one and the relationships that are construed in doing this amounts to learning something of cognitive importance in this activity. This fulfilment of the anticipation that they should see that something was happening also meant that the children were going in, what they found to be the right direction. So in finding this cognitive relationship, apart from expressing children's joy, the aesthetic judgements also communicated that the children found that these relations were the normatively right things to discern in this situation. That the children seemed to agree on this can be seen because the words the children used stood fast. They did not ask each other neither about what they meant by their observations about "bubbles" and "carbonic acid," nor about the meaning of the aesthetic utterances "Wow" or "Jeez, that's wild." Seen in this way, children through aesthetic judgements can be understood to regularly communicate what they find relevant to learn and at the same time how their work is progressing. Such reports were important in summing up relationships in moments of fulfilment.

The children also gave aesthetic advise, which amounted to a communication of anticipation about the aesthetic experience of fulfilment that could be expected from acting in the right way. Pernilla, when looking at salt, for instance, advised Anders in aesthetic terms about how to use the magnifier when observing different materials to decide whether they were solids or liquids in the Solids and Liquids unit:

6. Pernilla: Look over here and put it like this and look at it.

7. Anders: That's what I'm doing.

8. Pernilla: It's awesome.

When Pernilla showed Anders how to use the magnifier, she expressed the fulfilment of her anticipation about what you would see if you used it properly in positive aesthetic terms: "It's awesome." The aesthetic judgement used thus summed up the whole experience and involved learning how salt crystals look, which is a prerequisite for sorting out if they are solids or liquids. In addition it incorporated norms, as using the magnifier was something to be included in the observation in order to proceed with the activity in the right way. Moreover, using the magnifier in the right way also led to a pleasurable experience, which means that it was worthwhile observing salt crystals. Hence, aesthetic judgements were not only emotional as opposed to cognitive or conceptual propositions that are factual, but instead they were continuous in the experience as a whole.

\section{Negative Aesthetic Experiences}

Generally positive aesthetic judgements were used in relation to actions, objects and events that the children found belonging to science class and leading the science activity in the right direction. However, making distinctions did not only entail deciding what belonged to science class, it also entailed finding out what did not belong and what led in the wrong direction. To this end negative aesthetic judgements were used. Sanna used negative 
aesthetics when communicating to the teacher that she did not succeed in arranging the electric circuits in her carton house, which she built:

9. Sanna: No but. Oh! [angrily] I'm getting angry. I'm going nuts. Oooh! [angrily] So then... Oh, [impatiently] no good. Can you help me? This has to go in. It's stiff.

10. Teacher: Okay now?

11. Sanna: Sort of.

12. Teacher: Mm.

Sanna used negative aesthetic judgements in showing her frustration of not succeeding to proceed with the activity as was demanded of her. Sanna knew what to include but had problems in doing the coupling, as it was hard to put it together. Moreover the negative aesthetic judgements were used in order to get some help, for example, from the teacher, which Sanna obviously expressed when talking to the teacher. If children often are experiencing that they do not succeed in science class, there is a risk that they turn away from science learning, thinking that they do not belong.

However, when children are learning to distinguish that they can avoid aesthetics leading in the wrong direction the negative aesthetic experience does not need to be a threat, but instead something they can handle and sort out anticipating a fulfilment. One example came from Jonathan and Erik in the Soil unit investigating a soil sample. Here Jonathan sometime used positive aesthetic judgements and sometime negative ones when sorting out what to include and exclude, respectively, in finding out what type of soil they had got:

13. Jonathan: Now we're going to make a ball.

14. Teacher: Yeah. Here. [inaudible]

15. Erik: There's just water coming!

16. Teacher: Mm. Do you know why?

17. Jonathan: You took too much water.

18. Teacher: Well. Mm.

19. Erik: Mm.

20. Jonathan:... Oh, disgusting...Yuck...What are you doing?...This was neater.

21. Erik: Yeah.

In this encounter Jonathan construed the negative aesthetic judgements "disgusting" and "Yuck" to Erik's effort at making a ball of the soil. His previous experience from investigating different kinds of soil was here transformed. Using too much water did not carry the activity in the right direction, but instead you should use a sufficiently quantity of water which was "neater," that is, then you could sculpture the soil into a ball, which stood fast to the boys. The boys knew from previous experiences that the ability of rolling, or not rolling, soil into balls was important when identifying soil types, and thus was a step in the right direction in sorting out what the soil sample consisted of. The aesthetic judgements used were standing fast and Erik agreed to Jonathan's utterance that it was "neater" using less water. In that way they were able to classify the soil sample as containing at least clay, though they did not explicitly mention that. Hence, the positive aesthetic judgement "neater" at the same time was related to a momentarily consummation, but also to expectations about how to get the activity proceeding, that is, how the whole activity in time would lead to a consummation. By alternating between positive and negative aesthetic judgements Jonathan was able sorting out what did and did not belong in the investigation 
and thus what was the right way to proceed with the activity in finding out what type of soil they had got. In that way they would come to a fulfilment and reach the purpose of the lesson. Hence, an aesthetic experience is situated in the whole activity and in learning what to exclude or include. When participating in an activity we simply act and feel without separating emotions, our doings and cognitive aspects from each other, but they are forming a whole.

It was obvious that the aesthetic judgements used on all of the so far mentioned occasions in a trivial sense were mundane. Nevertheless, the use of aesthetic judgements stood fast to the children in these situations, although the situations were new to them. In this way the aesthetic judgements helped the children to make sense and communicate what occurred and to make relevant distinctions about which things, events and actions belonged in the science class. They were thus an integral part of learning science in class. Hence, an aesthetic experience is not just about a subjective, inner feeling, but related to a sort of habit of experiencing and communicating aesthetically. Those habits are closely connected to which direction learning is taking during an activity to move to fulfilment and consummation.

Teachers' Use of Aesthetic Judgements

Teachers likewise frequently used aesthetic judgements to help their students to distinguish what belonged and did not belong in science class. One way the teachers used aesthetic judgements was to confirm that a child had made a relevant discernment. During the Buds unit the children were supposed to describe their tree buds and later on to follow what happened to the buds in order to learn about the life cycle of a tree. In the following excerpt the teacher asked Jesper to describe the bud of his tree, that is, hazel:

22. Teacher: And Jesper, what kinds of buds do you have?

23. Jesper: Green.

24. Teacher: You have fine green buds.

The teacher acknowledged the description given by Jesper by using a positive aesthetic judgement. Through this judgement the teacher did not only confirm that the bud was green but also that colour was a relevant category to distinguish in giving a description of buds in science class. Hence, the teacher used an aesthetic argument in discerning which were the right things to include during the observation of the bud. In this way the teacher did not only confirm that Jesper was going in the right direction, but also shared the joy of fulfilment with the children, summing up the descriptions of the bud that carried the science unit forward. Accordingly the aesthetic judgement is not only about confirming that the children cognitively and conceptually are proceeding in the right direction, but also about an aesthetic consummation if you succeed with the task of the lesson. This is a question about taste, buds are fine, which the children were learning from the teacher. Such an aesthetic experience, including emotions, norms, facts and aesthetic aspects, of course will have consequences for the children's proceedings with the activity - it is worthwhile studying buds and learning more about them.

Teachers used positive aesthetic judgements also when confirming that the children were acting in the right way. In the Buds unit for example, the teacher encouraged the children's positive aesthetic judgements in a moment of fulfilment by giving her own aesthetic judgement in confirming that the children used relevant methods for observing the buds and that they were using the magnifier properly in studying the buds. This aesthetic moment in 
using the magnifier resulted in Bosse noticing the new relation that his bud also had red colours:

25. Anders: Is it supposed to be like this?

26. Teacher: No! This lens is supposed to be closest to your eye. Then you'll see really well.

27. Eva: I can see!

28. Teacher: You may borrow this so you can also look at the buds.

29. Eva: Wow!

30. Teacher: There you go! [inaudible] Also look at the buds...Yes, just super! Did you see!

31. Bosse: Wow!

32. Teacher: It's super. Can you take it?

33. Bosse: Mine have red in it too.

34. Teacher: What do you see, Bosse? ... If you were going to talk about your buds.

35. Bosse: Red.

By the aesthetic judgements the teacher could be said to help the children to approach a more scientific language game not only about the scientific content to be learned (knowing magnifiers and buds), but also aesthetically by sharing their feelings of joy in doing science. When pointing out that observing buds was "just super" the teacher encouraged the children aesthetically about the delight of looking at buds. This resulted in Bosse making a close observation discerning more details of the bud, and also the children learning aesthetically about buds, that is, they were pleasing to observe. In addition the children learnt that they belonged to science class and that it was fascinating studying buds.

By their aesthetic judgements the teachers regularly not only evaluated the result of their children's work, but also their ways of working. One situation where this occurred was in the Electric Circuits unit, where the children were supposed to build a small house with lamps inside their rooms. They had earlier investigated what kind of materials conduct current and had worked with parallel couplings and series connections and should now use their knowledge to give light in a carton house. In this transcript John wanted to show the teacher their house:

36. John: Christina [the teacher]! Come and look at ours!

37. Teacher: Very nice looking! Very neatly done! We have a real house here.

38. John: Mm.

39. Teacher: Mm.

The teacher here confirmed that the house was "nice" and "neatly" done, not explicitly commenting on the scientific endeavour of the lesson though, that is, giving light to lamps in the house. Anyway, the teacher evaluated the children's work by construing relations uttered in positive aesthetic judgements. In doing this she confirmed that the children were proceeding in the right direction and simultaneously encouraging them in carrying on with the activity, tacitly anticipating that the children should make electrical couplings as well.

\section{Discordant Aesthetic Experiences}

Learning science in science class often meant learning new aesthetic relations. Many of these relations dealt with whether the children wanted to deal with the objects, events and actions of science class, that is, with children's possibilities of participating. Some of these negative aesthetic experiences meant that children had difficulties in carrying on with the 
activity, that is, to participate in the work of science class. Such negative aesthetic experiences we call discordant aesthetic experiences because children could not make their own personal aesthetic taste tally with what was demanded of them in class.

Discordant aesthetics can be dissolved and transformed either through getting used to the object, event or action, or through inventiveness. One example, where these two ways of learning aesthetically were combined, came from Julia examining earthworms in the Soil unit. It involved the transformation of the first discordant negative judgements of Julia in relation to the earthworms she had to handle during the Soil unit. The children were to observe an earthworm and describe how it looked and how it behaved. When first encountering the earthworms she found them disgusting and had difficulties in carrying on with the task. Her classmate Emma on the other hand related to the earthworm in positive aesthetic terms:

40. Julia: How disgusting!

41. Emma: I can hold it in my hand.

42. Julia: No! I can, I dare to, but it's disgusting. It can go here. You can keep it here on the paper instead.

43. Emma: I think it's nice to hold it.

44. Julia: Ooooh! [sighs]

As can be seen from this excerpt, Julia was provoked by Emma to say that she also dared holding the earthworm - she was no coward, but she found it disgusting. To solve the problem she came up with the solution of placing the earthworm on a paper. Nevertheless, Emma maintained that it was not a question of daring, but whether the experience you have was pleasant or not. While Julia established the negative aesthetic relation of "disgusting" specifically to holding the earthworm, Emma construed the positive aesthetic relation of "nice" to the act of holding the animal. Julia then sighed when learning this. Next Julia needed to remove the soil that was on her earthworm in order to be able to observe it better. This forced the girls to handle the earthworm, and Emma helped Julia in cleaning hers, although even Emma found this a bit repellent, as could be seen from her saying "Yeck":

45. Julia: I'll try to get off a bunch of dirt.

46. Emma: Yeah.

$[\ldots]$

47. Julia: Yes, look! Try and get the dirt off. Then it's easier to look at it.

48. Emma: I'm trying. Eeeooo [with a feeling of disgust], how nice!

49. Julia: [giggles with disgust]

50. Emma: Yeck. It's clinging to me.

Then their relations to the earthworms took a positive turn. Julia found that her earthworm was injured. This made her pity it in positive aesthetic tones. This positive aesthetic relation led on to her now giving positive aesthetic judgements in relation to it as "cute" and "little" giving it the pet name Oskar. This resulted in that also Klas and Emma of this group gave their earthworms names and related to them in aesthetic terms, actually competing about whose earthworm was the cutest:

51. Julia: Look, look. It's really injured. It's going to die soon. [tender voice]

52. Emma: No! All worms are [inaudible - immortal?].

53. Julia: No, not this one. He's so cute...Little Oskar. 
$[\ldots]$

54. Klas: I have two.

55. Emma: Oh, [anxiously] look! It's so terribly cute. I think this is the head.

56. Julia: Yeah, that's the head.

57. Emma: Yes, look!

58. Teacher: Are they cute?

59. Julia: Y-e-s!

60. Emma: There's the bump he talked about.

61. Teacher: Do you think it's cute Klas?

62. Klas: I've always thought that worms are cute. They look supercute.

63. Julia: Mmm.

[Emma and Julia christen Emma's worm Ville Knut. Klas christens his two Play Station and Sigge.]

64. Julia: They [Oskar and Ville Knut] are cute.

65. Klas: No way. They're not cuter than Sigge.

66. Emma: You shouldn't have two of them.

While involved in this language-game of relating aesthetically to their earthworms as pets, they at the same time started to observe them. In turns 55-57 Emma and Julia noticed the head and in turn 60 Emma observed that her earthworm had a "bump." Noticing the head and the "bump" might seem unimportant, but due to the children's low age this was a starting point in observing the morphology of earthworms. But the children also learned aesthetically about their possibilities of partaking in studies of earthworms and that they are cute. Taken together, in this sequence where the children were supposed to make observations of their earthworm, there were a number of situations that the children had to relate to aesthetically. In these encounters with the earthworm, the aesthetic relation varied back and forth between positive and negative judgements as the children proceeded in action. From cleaning the earthworm from soil in turns 45-50, Emma learned that she also could have difficulties in handling earthworms. Julia had to learn ways of making observations of her earthworm without touching it. This gap needed to be filled so she could proceed with what was demanded of her in science class, that is, to be able to participate. Julia filled this gap by using a paper and by the help she received from Emma in cleaning her worm. The make-believe game she invented of treating her earthworm as a pet in need of help also helped her filling this gap. All these aesthetic relations to the earthworm needed to be learnt in action and to be transformed in such a way that the children could proceed with the science task at hand.

It should be obvious that if discordant aesthetics is not being transformed, the activity halts or will need coercion to continue. In such instances aesthetics have morale consequences, when children are driven to do things they find wrong or disgusting. The reverse is also possible, namely what children are finding aesthetically positive, is aesthetically negative to science. Then there is a conflict between what the children are discerning and the scientific purpose of the activity. Hence, if children are not able to sort out the scientific context from other contexts, the activity will go astray. This concerns how people's aesthetic judgements and experiences differ in different situations depending on the activity they are participating in.

\section{Genre Awareness}

In the above example considering the earthworm it was obvious that the children slowly were learning that earthworms are cute. It gradually also became evident that such an 
aesthetic is not closely tied to the object itself - the earthworm - and its inherent qualities, that is, that the children once and for all had learnt that earthworms actually are cute. As proposed by Wittgenstein (Wittgenstein 1966, 1967) a word's meaning is not what it represents, but it gains its meaning through its use in an activity. Hence, the aesthetic relations to an object, event or action were not given by the object per se, so that a child always found the same aesthetic quality in a certain object, event or act. Instead it was highly situational and depended on the circumstances and the language game. This was illustrated by the following excerpt from another group of children studying the earthworm during the Soil unit:

67. Teacher: Do you think that the worm, is it cute?

68. Rickard and Tim: Yes!

69. Teacher: Why don't people have worms as pets?

70. Rickard: They're too little.

71. Tim: Maybe they're a little disgusting.

Apparently the children here construed relations to the earthworm in positive aesthetic terms in class work, but not when they considered the possibility of having them as real pets. Accordingly doing science does not just mean conceptual understanding, but also learning aesthetically about, in this case, earthworms. When learning that earthworms are cute in science class, the children of course might look upon earthworms as disgusting in another situation. This example is showing that the aesthetic judgements in school and elsewhere only can be understood as parts of whole activities and not as universal descriptions of qualities of objects or the state of mind that always will occur together with a specific object.

As aesthetic judgements are closely tied to the situation, the aesthetics of whole activities might clash. This might happen when children are not willing to replace their aesthetic discernment made in one activity by an aesthetic discernment possible to make if you view the activity from another angle. One example came from the unit Electric Circuits, where Nicolai and the teacher did not share the same aesthetics, uttered in aesthetic judgements:

72. Teacher: Aha. Did you decide on one more lamp, or?

73. Nicolai: Well...shall we take another lamp?

74. Joachim: It should go up here.

75. Nicolai: Yeah.

76. Teacher: Shouldn't you have a lamp down here?

77. Nicolai: No, look, no look. It doesn't work as well, for sure.

78. Teacher: How can you get that lamp to light?

79. Nicolai: But that's no good since it doesn't...it won't be as cosy then.

80. Teacher: You mean when someone peeks in?

81. Nicolai: Yeah.

82. Teacher: But someone can. You can make a window here maybe. Cover it here.

83. Nicolai: But then you can't keep tinkering. ${ }^{2}$

84. Teacher: No, that's true, you can't.

\footnotetext{
${ }^{2}$ The original Swedish word Nicolai used was "pyssla," which has a connotation of tinkering in a cosy way. We have found no corresponding word in English.
} 
As can be seen from this excerpt the conflict of interest between Nicolai and the teacher was one about aesthetics and taste. Nicolai in turns 79 and 83 was trying to fill a gap between his house and it being "cosy" and also being a place where you could be "tinkering." The teacher in turn 78, on the other hand, was trying to make Nicolai noticing gaps in relation to the scientific content, that is, of electric circuits, by having him put in another lamp (turn 76). However, in doing this the teacher got involved in aesthetic arguments with Nicolai, who evidently was not convinced as can be seen in turn 83 . Instead the teacher finally had to agree with Nicolai in turn 84 . In this example it is as if two language games of what constitutes an aesthetically pleasing fulfilment clashes. One is the teacher's, where the fulfilment is one of making lamps to light, the other one is that of Nicolai, where consummation amounts to making a "cosy" house, where you can play make-believe of "tinkering." In this case, the play invented, and its aesthetic aspects, did not carry Nicolai's activities in the direction desired by the teacher, that is, connecting more lamps in the house in order to learn about electric circuits. The teacher did not succeed in making the children in Nicolai's group notice a gap, but used an aesthetic language, which did not make the conversation proceed in the direction first desired by the teacher. Hence there were different anticipations in relation to the two activities with their different purposes, which consequently led to partly different discernment considering which objects, events and actions that should be attended to. Being involved in making a "cosy" house, hindered the children from aesthetically distinguish what would lead to a fulfilment of the scientific part of the activity.

According to a cognitivist view, where emotions are seen simply as the motor of an activity, rewarding us to keep on with it, this is unproblematic. However, the children's everyday aesthetics of making a house cosy did not always tally with the aesthetics of doing science in the classroom, that is one of anticipation and fulfilment involving relations of scientific content like making a circuit with more than one lamp.

Another example where the aesthetics of the teacher did not tally with that of the children's came from the Buds unit. The teacher suggested an aesthetic relation concerning the hazel female flower to the children Bosse and Calle, but it did not carry these children in the descriptive direction first suggested by the teacher:

85. Teacher: This one is nice. Do you see it up here? It's really nice. Look at it... How many little hairs does it have? Do you see that?

86. Calle: No!

87. Teacher: It's really pretty that twig.

88. Calle: What should I do now?

89. Teacher: Now you can write something about the twig. You can write what you think it looks like.

90. Bosse: N-o-o-o!

91. Calle: It looks like a caterpillar.

92. Teacher: Yes, you can write that.

In normative uses, concerning what children should do and not do in science class - and about what distinctions should be made - positive aesthetic judgements were used about what should be included. In the above example the teacher was using positive aesthetic judgements in trying to encourage the children to make more discernment considering the bud. However, in this encounter the teacher's expectation did not work as the children did not nibble at the teacher's attempt, but the communication ended up in what was going to happen next. Apparently the teachers' aesthetic judgements did not make sense to every 
child, and they did not partake in the positive stance of the teacher, who in using positive aesthetic judgements tried to encourage the children making a closer observation. Instead they wanted to know what to do next. Hence, just as is the case with learning scientific concepts in the restricted sense, many such aesthetic distinctions needed to be learned as part of learning science.

\section{Aesthetic Judgements as Cognitive Descriptors}

Although we focus on how aesthetic experiences were continuous with learning normative relations and the possibility of participating in science class, it needs also to be pointed out that aesthetic judgements often were inseparable from factual ones when describing qualities of what was observed. Aesthetic judgements were used as cognitive descriptors by both children and teachers. One example came from Soil class where Kalle and Erika tried to find the right word to characterise the soil type at hand for future identification:

93. Kalle: Yes. No, that feels like sand and clay? Do we write that?

94. Erika: I'm going to write that it feels soft and gooey and looks like clay.

95. Kalle: Or...It feels...

96. Erika: We should feel a little...It feels soft...soft.

97. Kalle: How do you write feels? How do you write feels?...[comes over to first author and asks how "feels" is spelled]

98. BJ: What should you write?

99. Kalle: It feels soft. It feels nice. Feels, feels.

100. BJ: Mm.

Apparently "gooey," "nice" and "soft" each stood fast and could be used as meaningful factual descriptors in this situation, although "nice" is an aesthetic judgement, which would seem to be highly subjective. However, as long as the children could make use of their descriptors, they were functional to them. In this encounter the children in that way were able to talk about the soil sample they had got, describing how it felt touching, though not using scientific concepts, and thus they could carry on with the activity. From their earlier experiences of investigating sand and clay, they knew how it felt touching the different items. Hence, talking about the feature of soil, using adjectives, also aesthetic ones, as cognitive descriptors, helped the children to sort out what kind of soil they were investigating.

Just as was the case with children, also to the teachers the distinctions between aesthetic judgements and factual judgements were blurred. One example was the description the teacher gave during the Buds unit of the male and female flowers of the hazel:

101. Bosse: What's this?

102. Teacher: Yes, what is this? Shall I say what it is?

103. Gunilla: Y-e-s!

104. Teacher: On this twig are girls and boys. The boys, those are the ones that are hanging. The girls are the ones with neat hair. The ones that have a tuft here.

105. Gunilla: $O h$ ! [in wonder] Eva, you get that one.

Apparently the aesthetic fact that female flowers are "the ones with neat hair" made sense to the children. However, that such aesthetic experiences expressed in aesthetic judgements describing qualities of what was observed did not necessarily make sense to 
every child was clear from the earlier mentioned turns 85-92. Obviously the children could not always relate aesthetically in the positive way of the teacher. The children could thus not always participate in the teacher's language-games and make the aesthetic relations suggested by the teacher. Again, it should be emphasised that many aesthetic relations needed to be learned.

\section{Discussion}

In this study we have shown that children and teachers of elementary school, like university students and teachers (Wickman 2006), frequently use aesthetic judgements when talking science. Aesthetic experiences have consequences for further meaning making in science class as well as for learning norms and about the possibility of participating. The use of aesthetic judgements in science class thus should be of interest to both researchers and teachers at all levels of education for several reasons.

First, aesthetic experiences are heavily integrated into experience generally. Consequently it is important that teachers pay attention to the aesthetics of children and bring it to light in discussions continuously during science activities. The reason is that most aesthetic experiences are situated. Their dependence on the context was clearly shown when Richard and Tim found the earthworm sweet in the scientific context, but disgusting as a pet (turns 67-71).

Second, learning the aesthetics of science class means using ordinary language but in a new sense to make distinctions relevant in science class. Judgements, as for instance "nice" and "disgusting," might seem trivial, but as pointed out by Wittgenstein (1966), they are of great significance in the situation they are uttered. One example of the significance of aesthetic judgements when learning science came from Jonathan (turn 20), uttering that it was "neater" to use less water when trying to roll the soil sample into a ball in order to sort out what the item consisted of. The example with the installation of electric circuits into a cardboard house and the distinction between earthworms as pets and in science class showed that children also had to learn to distinguish the aesthetics of science class from the aesthetics of other kinds of activities, that is, learning an awareness of genre. Accordingly, when learning science, you also learn to aesthetically, and communicatively discern what to include and exclude and what does belong and what does not belong in science class. In this way aesthetic experience is continuous with learning to observe in science class. Hence, aesthetic experiences are closely involved with children's learning of normative dimensions of science.

Third, as aesthetic experiences are so intimately connected to the fulfilment of a task and of learning new things, aesthetic experiences should also be a powerful ingredient in evaluating what children learnt in science class, including normative aspects. Because the normative aspects in activities are crucial for which direction learning takes (Rogoff 1990; Wickman 2006), learning norms in science class is of great importance in relation to the scientific content to be learned.

Fourth, norms when expressed in aesthetic judgements during an activity, are immediate and of short duration. In spite of this they should result in continual transformation of the relation between the child and science class in such a way that it in the long run might either result in habitual engagement or in permanent disengagement. The results suggest that we should look closer at the possibility that interest in school science does not come as a lightning flash, but is slowly learnt in the numerous aesthetic encounters of science class. Aesthetic experiences are intimately interwoven - for good or for worse - with children's 
possibilities of participating in science education as also Girod and Wong (2002) and Bloom (1992) emphasise. Our results show that children during all the small aesthetic encounters learn whether they can continue with science activities or not. The aesthetic judgements of children thus are an important indicator of what they are learning in regard to themselves in science, which is a question of identity, that is, learning about your own place in relation to science (Brickhouse et al. 2000; Wickman 2006). But it does not help a teacher just to render science in positive aesthetic terms during a lesson, as positive aesthetic expectations mediated by the teacher in the long run only could gain meaning to the children if resulting in positive aesthetic fulfilment, where the children themselves are given experiences that make sense to their scientific activities as a whole, including also the cognitive dimensions (Wickman 2006). The example from the Buds unit illustrates this, where the teacher aesthetically tried to encourage the children making a closer observation of the buds (turns 85-92). Another example was when the teacher in the unit Electrical Circuits did not succeed in getting the children to agree with her aesthetic judgements concerning the scientific part of the activity. This shows how important a teacher's own aesthetic experience and imagination is in carrying children's learning forward in the right direction. Besides, negative aesthetic experiences are inescapable in learning, but in the long run they either need to be avoided or transformed into positive ones (Wickman 2006). One example of such a transformation came from Julia, Klas and Emma observing earthworms (turns 51-65). If they had not been able to sort out their problem of handling the earthworm, the science activity would have come to a halt. Hence, it is of great importance that teachers are acknowledging those situations where children are using negative aesthetic judgements and are unable to proceed with and participate in the science activity. This should be seen as a warning signal, and as a consequence the teacher should consider if the teaching situation needs to be reconstituted. Teachers could also pose questions as "Why do you think it is disgusting?," bringing the children's emotions to the fore and helping them to avoid or transform their aesthetic experience into a positive one. However, children's negative aesthetic judgements do not always mean that they rather would stop doing science than proceeding with the activity. Instead they are also used when sorting out what to exclude from science (turn 20). Accordingly it is important for teachers to notice in what way children are expressing themselves in negative aesthetic judgements.

Fifth, just as a teacher explores the alternative conceptions of children, it might be equally important to start a science unit bringing the aesthetic experiences of children to the fore. As well as teachers bringing up the scientific concepts to discussion, likewise they could bring up children's aesthetics. That gives the children an opportunity to share aesthetic experiences in science class, talking about previous experiences and as well giving each other aesthetic advise when proceeding with the activity (e.g., turns 6-8). If the teacher had noticed what happened when Julia and Emma observed earthworms (turns 40 44 ), she could have brought their solution in a playful manner to other children in class having difficulties in dealing with the earthworms.

Sixth, as was the case concerning university teachers (Wickman 2006), elementary school teachers frequently used positive aesthetic judgements to help the children discern what belonged in science, what was relevant, and to evaluate or confirm that the children made appropriate distinctions. In order to do that they, like university teachers, students and children, used everyday aesthetics when talking science in the classroom. One example came from the Buds unit, where the elementary school teacher confirmed that the child, who observed that the bud was green, was going in the right direction when saying "You have fine green buds." This also applies to confirming the children's way of solving their science tasks: "Very nice looking! Very neatly done!" (turn 37). The elementary school 
teacher's expression "You have fine green buds." also meant that the child had distinguished what was relevant when he observed buds, namely the colour. Such aesthetic remarks were common when teachers judged children's participation in science class, that is, how children acted and made distinctions in science class. It should be emphasised that through such judgements teachers do not just direct children to fulfilling scientific experiences, they also share their own joy.

Finally, normative and cognitive aesthetic judgements are often continuous and regularly merge. When aesthetic judgements were used as cognitive descriptors they were interwoven with regulative aspects related to the children's course of actions and hence they were also normative. Both elementary school children and university students (Wickman 2006) sorted out relevant and irrelevant scientific facts in using aesthetic judgements. The children of the current study used aesthetic judgements as cognitive descriptors, like "It feels nice," when trying to characterise the soil type at hand. The aesthetic everyday language constituted a bridge between experiences in science class and previous experiences, which should be noted by teachers to make the judgements continuous.

To sum up, our study strongly supports Bloom's (1992) contention that emotions, values and aesthetic experiences are interrelated in children's learning and also related to cognitive aspects of learning. We herein also have shown that aesthetic experiences in elementary school science are continuous with learning science more broadly, involving transformation of the scientific content learned and norms about how to proceed in science class. Aesthetic experiences as seen in action in science class shows how the interlocutors are struggling with whether they can participate in the activity at hand or not, that is, if they are emotionally for or against the different situations of the activity. If the children are not able to distinguish what to include and exclude, or are learning that they do not belong to science class, this will have consequences for their further learning and meaning-making in science. Hence, a study of aesthetic experience in science class can contribute not only to our knowledge of science learning as conceptual change, but also to our understanding of the transformation of the values of the whole person, as involved in the activities of science class. These are the reasons why aesthetic experience in science class should be of central interest to science educators.

\section{References}

Alsop, S., \& Watts, M. (2003). Science education and affect. International Journal of Science Education, 25, $1043-1047$.

Bloom, J. D. (1992). The development of scientific knowledge in elementary school children: A context of meaning perspective. Science Education, 76, 399-413.

Bourdieu, P. (1984). Distinction: A social critique of the judgement of taste. London: Routledge.

Brickhouse, N. W., Lowery, P., \& Schultz, K. (2000). What kind of a girl does science? The construction of school science identities. Journal of Research in Science Teaching, 37, 441-458.

Cobern, W. W., \& Aikenhead, G. S. (1998). Cultural aspects of learning science. Dordrecht, The Netherlands: Kluwer.

Dewey, J. (1934/1980). Art as experience. New York: Perigee Books.

Dewey, J. (1938/1997). Experience \& education. New York: Touchstone.

Gardner, H. (1971). Problem-solving in the arts and sciences. Journal of Aesthetic Education, 5, 93-113.

Girod, M., \& Wong, D. (2002). An aesthetic (Deweyan) perspective on science learning: Case studies of three fourth grades. The Elementary School Journal, 102, 199-224.

Jakobson, B., \& Wickman, P.-O. (2007). Transformation through language use: Children's spontaneous metaphors in elementary school science. Science \& Education (in press).

Lave, J. (1996). The practice of learning. Cambridge, UK: Cambridge University Press. 
Lemke, J. L. (2001). Articulating communities: Sociocultural perspectives on science education. Journal of Research in Science Teaching, 38, 296-316.

Lidar, M., Lundqvist, E., \& Östman, L. (2006). Teaching and learning in the science classroom: The interplay between teachers' epistemological moves and students' practical epistemology. Science Education, 90, $148-163$.

McClure, A. A., \& Zitlow, C. S. (1991). Not just the facts: Aesthetic response in elementary content area studies. Language Arts, 68, 27-33.

Mortimer, E. F., \& Scott, P. H. (2003). Meaning making in secondary science classrooms. Maidenhead, UK: Open University Press.

Novak, J. D. (2002). Meaningful learning: The essential factor for conceptual change in limited or inappropriate propositional hierarchies leading to empowerment of learners. Science Education, 86, 548571.

Posner, G. J., Strike, K. A., Hewson, P. W., \& Gertzog, W. A. (1982). Accomodation of a scientific conception: Toward a theory of conceptual change. Science Education, 66, 211-227.

Rogoff, B. (1990). Apprenticeship in thinking: Cognitive development in social context. Oxford, UK: Oxford University Press.

Root-Bernstein, R. S. (1989). Discovering. Cambridge, MA: Harvard University Press.

Roth, W.-M., \& Lucas, K. B. (1997). From "truth" to "invented reality": A discourse analysis of high school physics students' talk about scientific knowledge. Journal of Research in Science Teaching, 34, 145179.

Strike, K. A., \& Posner, G. J. (1992). A revisionist theory of conceptual change. In R. A. Duschl \& R. J. Hamilton (Eds.), Philosophy of science, cognitive psychology and educational theory and practice (pp. 147-176). Albany, NY: State University of New York Press.

Szybek, P. (1999). Staging science. Some aspects of the production and distribution of science knowledge. Unpublished doctoral dissertation, Lund University, Lund, Sweden.

Säljö, R., \& Bergqvist, K. (1997). Seeing the light: Discourse and practice in the optics lab. In L. B. Resnick, R. Säljö, C. Pontecorvo, \& B. Burge (Eds.), Discourse, tools, and reasoning: Essays on situated cognition (pp. 385-405). Berlin, Germany: Springer.

Tauber, A. I. (Ed.) (1996). The elusive synthesis: Aesthetics and science. Dordrecht, The Netherlands: Kluwer.

Wertsch, J. V. (1995). The need for action in sociocultural research. Cambridge, UK: Cambridge University Press.

West, L. H. T., \& Pines, A. L. (1983). How "rational" is rationality? Science Education, 67, 37-39.

Wickman, P.-O. (2004). The practical epistemologies of the classroom: A study of laboratory work. Science Education, 88, 325-344.

Wickman, P.-O. (2006). Aesthetic experience in science education: Learning and meaning-making as situated talk and action. Mahwah, NJ: Erlbaum.

Wickman, P.-O., \& Östman, L. (2002a). Learning as discourse change: A sociocultural mechanism. Science Education, 86, 601-623.

Wickman, P.-O., \& Östman, L. (2002b). Induction as an empirical problem: How students generalize during practical work. International Journal of Science Education, 24, 465-486.

Wittgenstein, L. (1966). Lectures and conversations on aesthetics, psychology and religious belief. Oxford, UK: Blackwell.

Wittgenstein, L. (1967). Philosophical investigations. Oxford, UK: Blackwell.

Wong, D., Pugh, K., \& the Dewey Ideas Group at Michigan State University. (2001). Learning science: A Deweyan perspective. Journal of Research in Science Teaching, 38, 317-336. 